\title{
Use of Chlorhexidine Solution as an Additional Step in Combination with Conventional and Two or Three Step Adhesive Systems
}

\author{
Diogo de Azevedo Miranda ${ }^{1}$, Ana Paula Bartocci ${ }^{2}$ \\ ${ }^{1}$ Adjunct Professor of Faculty of Medical Sciences and Health of Juiz De Fora/ SUPREMA \\ ${ }^{2}$ Student, Dental of Faculty of Medical Sciences and Health of Juiz De Fora/ SUPREMA \\ Department of Dentistry, Faculty of Medical Sciences and Health, Juiz De Fora, Brazil/ SUPREMA
}

\section{Address for correspondence:}

Dr. Diogo de Azevedo Miranda,

Rua Sampaio 330/602, Granbery, Juiz de Fora, Minas Gerais 36010-360, Brazil

\begin{abstract}
Adhesion to dental tissues is one of the main lines of research today, mainly the chemical evolution of adhesives, which allowed the restorative procedures to be performed with greater speed and predictability1. Bonding to dentin is a unique form of tissue engineering in which a matrix of demineralized collagen with residual crystals of hydroxyapatite is used as the basis for the infiltration of resinous monomers, forming the hybrid layer. Most adhesive systems currently available on the market produce good initial bond strength values, allowing the clinician to stick to the dental structure without the need for retentive preparation. ${ }^{[1]}$
\end{abstract}

Despite technological advances in adhesive materials, clinical and laboratory studies ${ }^{[2,3]}$ confirm the inexorable degradation of the bonding of the composite resin to dental tissues in the long term. ${ }^{[4]}$ The simplification of adhesive procedures was done at the expense of the use of more hydrophilic resinous monomers, responsible for the formation of hybrid layers with lower hydrolytic stability4. Ideally, the network of collagen fibrils exposed after conditioning with phosphoric acid should be completely infiltrated. However, it is known that there is a decrease in the diffusion gradient of the resinous monomers, creating defects at the base of the hybrid layer which manifest morphologically as an unprotected collagen zone. The collagen fibrils of this non-infiltrated zone show structural instability, since they are not enveloped by the resinous monomers. $^{[5]}$

For this reason, the reduction of bond strength of adhesive systems to dentin can be attributed to water sorption, hydrolysis of the resinous phase and degradation of the collagen network. ${ }^{[4,6]}$ Reactively, it was found that a family of proteolytic enzymes present in the dentin matrix can also contribute to the degradation of adhesive interfaces. Metalloproteinases (MMPs) have specific functions in the regulation of physiological and pathological mechanisms of collagen-bearing tissues, such as dentin mineralization. However, these enzymes may also have deleterious effects on the degradation of collagen and other extracellular proteins. ${ }^{[6,7]}$ MMPs can be activated by the acidity of conventional adhesive systems (mainly related to the previous application of phosphoric acid) and autocondicionantes, as well as by acid derivatives secreted by bacteria related to dental caries. ${ }^{[5]}$

Since the durability of the adhesive treatments is usually related to the quality of the hybrid layer, different operative maneuvers have been proposed aiming to increase the longevity of the toothrestoration interfaces: 1) reduction of water incorporation rate; 2) improvement in the quality of infiltration of the resinous monomers; and 3) reduction of dentin collagen degradation. ${ }^{[7]}$

Currently, the major focus of the studies is on the reduction of collagen degradation, seeking the inactivation of MMPs present in the dentin matrix through the use of specific inhibitors. Pashley et al. ${ }^{[8]}$ observed that chlorhexidine had inhibitory properties of the metalloproteinases and consequently preservation of the structural integrity of the collagen fibers, which could halt the degradation of the hybrid layer.

Since then, several studies have demonstrated that the degradation of dentin collagen can be reduced through the use of chlorhexidine solution on the dentin already conditioned by the phosphoric acid. Its main effect is the inhibition of metalloproteinases through a mechanism of chelation of calcium and zinc ions present in the dentin matrix. In addition to not interfering with the immediate values of bond strength, it makes the adhesive interfaces more stable over time, since it reduces the deterioration of the hybrid layer. The most used concentrations are $0.2 \%$ and $2 \%$, with the $2 \%$ solution being the most searched.

Chlorhexidine, at concentrations below 1\%, has bacteriostatic action, causing membrane damage and loss of low molecular weight substances, such as potassium and fluoride ions, although it does not produce the bacterial death. However, at concentrations above $1 \%$, it causes coagulation and cytoplasmic precipitation, producing cell death, being highly bactericidal. ${ }^{[4,6]}$ This substance acts on gram-positive and negative aerobic and anaerobic. It has several applications and, in the area of Restorative Dentistry, it has been indicated for the cleaning of cavities before they are restored, because it provides adequate disinfection of the dental tissues. In 


\section{International Journal of Innovative Research in Medical Science (IJIRMS) Volume 03 Issue 12 Dec 2018, ISSN: 2455-8737, Imp. Factor - 4.102 Available online at - www. ijirms.in}

carious lesions in which all infected structures were removed, it was suggested to apply this solution as a way to ensure the complete removal of remains of organisms that could be present in the cavity. ${ }^{[9,10]}$

The use of conventional adhesive systems in conjunction with chlorhexidine in the most diverse clinical situations has shown to be effective and without any impairment of adhesive quality over time. ${ }^{[11]}$ Basically, the operative technique consists of the acid conditioning of the dentin for 15 seconds, washing with water and light drying of the surface; The chlorhexidine solution is then applied with an applicator tip for 1 minute, followed by a slight drying, without washing, prior to the application of the conventional adhesive system (be it in two or three clinical stages).

However, more recent studies state the contrary, that this solution does not eliminate all the microorganisms, which can leave carious dentin and that the restorative material can be placed without compromising the efficiency of the restoration, ${ }^{[5,6,9]}$ since it has been proven that if tooth plaque contact with cariogenic microorganisms (regardless of amount and variance) is broken, the potential to prolong the disease is lost and, over time, stabilizes without pulpitis or pulpal necrosis. ${ }^{[3,4,5]}$

With this information, it can not be said that in clinical practice we are free to leave traces of infected dentin, but what we can guarantee is that the disinfection of the cavity with the application of chlorhexidine before the restorative treatment does not reach an entirely new stage required. ${ }^{[12]}$ However, the use of this substance is not contraindicated because it has been found that it does not decrease the adhesive quality of the restorations. ${ }^{[6]}$

For this reason, many companies invested in research and thus boosted the market introduction of adhesive systems - a selfconditioning and a conventional two-step clinical (Peak SE and Peak IC, Ultradent) - which contain a solution of $0.2 \%$ chlorhexidine. This could allow the elimination of the additional clinical stage of application of chlorhexidine separately, simplifying and decreasing the clinical time of the adhesive technique. This is an example of what we could call the "therapeutic adhesive system", since besides acting in the formation of the hybrid layer, it can also provide anti-enzymatic action of MMPs.

The incorporation of chlorhexidine as an additional step during the adhesive procedures is extremely promising and contradictory, since the clinical and laboratory results obtained interfere positively with the adhesive resistance over time. Some professionals may question the inclusion of a further operative step (since the adhesive technique is simplified more and more) during the adhesive procedure, however, research shows that the simplification of adhesive systems does not result in better clinical results. $^{[12,13]}$

In view of the constant advances in biological and technological knowledge in dentistry, it is essential that the dental surgeon always seek updated support in specialized literature to choose and correctly execute the adhesive techniques so that, in this way, he can practice an evidence-based adhesive dentistry with high clinical predictability.

\section{References}

[1] Ersin NK, Candan U, aykut a; Eronat C, Belli, S. No adverse effect to bonding following caries disinfection with chlorhexidine. J Dent Child. 2009;76(1):20-7.

[2] Kidd Ea, Fejerskov O. What constitutes dental caries? Histopathology of carious enamel and dentin related to the action of cariogenic biofilms. J Dent Res. 2004;83(Spec Iss C):C35-C38.

[3] de Castro Fl, de andrade MF, Duarte Júnior S1, Vaz 1G, ahid FJ. Effect of 2\% chlorhexidine on microtensile bond strength of composite to dentin. $\mathrm{J}$ adhes Dent. 2003;5(2):129-38.

[4] Carrilho MR, Carvalho RM, de Goes MF, di Hipólito V, Geraldeli S, Tay FR, Pashley DH, Tjäderhane 1. Chlorhexidine preserves dentin bond in vitro. J Dent Res. 2007;86(1):90-4.

[5] Komori PC, Pashley DH, Tjäderhane 1, Breschi 1, Mazzoni a, de Goes MF, Wang 1, Carrilho MR. Effect of $2 \%$ chlorhexidine digluconate on the bond strength to normal versus caries-affected dentin. Oper Dent. 2009;34(2):157-65.

[6] Carrilho MR, Geraldeli S, Tay F, de Goes MF, Carvalho RM, Tjäderhane 1, Reis aF, Hebling J, Mazzoni a, Breschi 1, Pashley D. In vivo preservation of the hybrid layer by chlorhexidine. J Dent Res. 2007; 86(6):529-33.

[7] Ricci Ha, Sanabe ME, de Souza Costa Ca, Pashley DH, Hebling J. Chlorhexidine increases the longevity of in vivo resin-dentin bonds. Eur J Oral Sci. 2010; 118: 411416.

[8] Pashley DH, Tay FR, Yiu CKY, Hashimoto M, Breschi 1, Carvalho R, et al. Collagen degradation by host-derived enzymes during aging. J Dent Res. 2004 Mar;83(3):21621

[9] Di Hipólito V, Rodrigues FP, Piveta FB, azevedo lda C, Bruschi alonso RC, Silikas N, Carvalho RM, De Goes MF, Perlatti D'alpino PH. Effectiveness of self-adhesive luting cements in bonding to chlorhexidine-treated dentin. Dent Mater. 2012;28(5):495-501.

[10] Gendron R, Greiner D, Sorsa T, Mayrand D. Inhibition of the activities of matrix metalloproteinases 2, 8, and 9 by chlorhexidine. Clin Diagn lab Immunol. 1999 May;6(3):437-9.

[11] Hebling J, Pashley DH, Tjäderhane 1, Tay FR. Chlorhexidine arrests subclinical degradation of dentin hybrid layers in vivo. J Dent Res. 2005 aug;84(8):741-6. Erratum in: J Dent Res. 2006 apr;85(4):384.

[12] Carrilho MRO, Carvalho RM, Goes MF, di Hipolito V, Geraldeli S, Tay FR, et al. Chlorhexidine preserves dentin bond in vitro. J Dent Res. 2007 Jan;86(1):90-4.

[13] Erhardt MC, Osorio R, Toledano M. Dentin treatment with MMPs inhibitors does not alter bond strengths to caries-affected dentin. J Dent. 2008 Dec;36(12):1068-73. 